\title{
ESCOLARIZAÇÃO BURGUESA E FORMAÇÃO
} OMNILATERAL

\section{Bourgeois schooling and multilateral formation}

André Rodrigues Guimarães *

\author{
Ilma de Andrade Barleta ** \\ Jaqueline Cruz Correia $* * *$ \\ Otávio Junior Brito dos Santos $* * * *$ \\ Roniel Vaz de Lima $* * * *$
}

\section{Resumo}

O objetivo deste artigo é discutir a função da escolarização na formação do sujeito. Para tal, evidencia-se o papel que hegemonicamente desempenha a escola no capitalismo: formar mão-de-obra para o sistema produtivo. Assim, é preciso compreender que as atuais reformas educacionais, desencadeadas a partir da crise do fordismo, longe de significar uma formação humana plena, mantém a unilateralidade da pedagogia burguesa. Em contraposição à função unilateral da escola burguesa, reafirma-se um projeto sócio-educativo unitário e omnilateral, que proporcione o desenvolvimento humano em todas as dimensões. Entretanto, para consolidação da educação unitária e omnilateral é indispensável a superação global do sistema sócio-metabólico

\footnotetext{
* Professor Auxiliar de Política e Legislação Educacional da Universidade Federal do Amapá (UNIFAP); mestrando do Programa de Pós - graduação em Desenvolvimento Regional pela UNIFAP. Email: andre@unifap.br.

**Professora Estadual do Amapá; mestranda do Programa de Pós-graduação em Desenvolvimento Regional pela UNIFAP.

*** Licenciada Plena em Pedagogia UNIFAP.

***** Professor Estadual do Amapá; graduando em Pedagogia pela UNIFAP.

****** Graduando em Pedagogia pela UNIFAP.
} 
de mercadorias, pois a lógica anti-humana é constituinte estrutural do capitalismo. A partir desta constatação, e tendo o materialismo histórico como fundamento teórico-metodológico de análise, aponta-se a função que a escola atual pode desempenhar em prol de um outro modelo sócioeducativo.

Palavras-chave: Escola unilateral. Escola omnilateral. Contradição.

\section{Abstract}

The objective of this article is to discuss the role of schooling in the human formation. To do so, the role played by the school in the capitalism is essentially enhanced: it produces workmanship for the productive system. Thus, we must understand that the current educational reforms, which were triggered from the Fordism and that are far from promoting a plain human formation, keeps the unilaterality of the bourgeois pedagogy. As opposed to the unilateral role of the bourgeois school, a unitary and multilateral socio educational project which provides human growth in all dimensions is reaffirmed. However, for consolidation of the unitary and omnilateral education, it is indispensable to the overcoming of the socio metabolic system of goods is a must, because the antihuman logic is constituent structural of the capitalism. From this, and having the historical materialism as a theoreticalmethodological foundation, the role that the current school may play for the other socio educational model is evident.

Keywords: Unilateral school. Multilateral school. Contradiction.

\section{INTRODUÇÃO}

Pretende-se com este trabalho fazer uma análise sobre a função da escolarização na formação do sujeito. Trata-se de compreender os objetivos formativos assumidos pelos sistemas escolares no que diz respeito ao ideal de homem e sociedade a serem construídos e consolidados. Para esta análise, evidencia-se que na sociedade capitalista a escola, hegemonicamente, 
assume a função de formar mão-de-obra para o mercado de trabalho, adequando o sujeito de forma instrumental e ideológica aos desígnios do Capital.

Combase nestas questões, expõe-se que o processo de reestruturação produtiva, iniciado nos anos 1970, impõe novas demandas de qualificação profissional, levando os sistemas educativos a reformularem-se com o intuito de atendê-las. Estas reformulações ainda que acompanhadas de um discurso de formação humana ampla, instrumental e intelectual, representam a manutenção da unilateralidade da escola burguesa. Neste sentido, o rompimento da subserviência hegemônica da escola aos desejos do capital só é possível a partir de um outro modelo societário: o socialismo.

Para uma melhor compreensão do que se apresenta estruturamos este trabalho em quatro partes. Inicialmente se faz algumas considerações, sustentadoras de nossas análises, sobre a função social da escola na acepção burguesa. Em seguida, esboça-se uma breve análise sobre 0 ideal de trabalhador na produção fordista e no toyotismo, evidenciando os objetivos educativos adequados a cada um destes padrões produtivos. $\mathrm{Na}$ terceira parte, em contraposição a função unilateral da escola burguesa (formação de mão-de-obra para o mercado de trabalho) são apresentados os elementos constituintes de uma escola unitária e omnilateral, a qual considere a formação humana em todas as suas dimensões. Considerando a impossibilidade de uma educação omnilateral na atual sociedade, esboçase na quarta parte a contribuição da escola na sociedade capitalista para a superação da opressão humana, trata-se de verificar os elementos que podem ser utilizados para a consolidação de ações sócioeducativas condizentes com o desafio de construir uma nova sociedade.

\section{Advento do capitalismo e a necessidade de escolarização do trabalhador}

Em decorrência da transição produtiva, ocorrida no final do século XV e início do século XVI, marcada pela decadência da economia feudal e pela instauração de um novo modelo econômico denominado capitalismo, emerge também a necessidade de se reconfigurar as estratégias de 
manipulação societal que irão garantir a efetivação e a perpetuação dessa nova forma de acumulação de riqueza, negando ao trabalhador o direito de usufruir de sua própria produção.

Nesse contexto, Ponce (2003) ressalta que diante da mudança no modo de produção foi preciso repensar a educação oferecida às massas, pois nesse momento não se podia mais excluir esses indivíduos da instrução escolar, como ocorreu na Antigüidade e no Feudalismo. As ferramentas de trabalho no capitalismo que se instalava exigiam do trabalhador o domínio (ainda que elementar) de novas habilidades produtivas, as quais demandavam uma preparação cada vez mais científica.

Assim a escola, antes espaço de pequenos grupos e sob a Ordem da Igreja, não atendia aos interesses daqueles que agora compõe e regulam a esfera de dominação econômica. Desse modo, a escola tornando-se o lócus central de formação de mão-de-obra, passa a propagar o caráter repressor da educação burguesa. Diante desta constatação Ponce evidencia que "a classe que domina materialmente é também a que domina com a sua moral, a sua educação e as suas idéias” (2003, p. 169). Assim sendo, expõemse o caráter subserviente do Estado, e conseqüientemente da educação, aos interesses hegemônicos do Capital.

Com isso, ainda que propagado pelo Estado burguês a necessidade da escolarização da população como mecanismo de ascensão sóciocultural é preciso revelar que a educação burguesa oferecida às massas apresentava propósitos que representavam os interesses da minoria (os dominantes), camuflando-se os objetivos opressores de expropriação da força de trabalho e da formação de um povo gentil e dócil, em nome da necessidade de apropriação da cultura.

Sabemos o que significava nas mãos da burguesia "liberdade da criança", "formação do homem", "direitos do espírito". A imagem do novo homem que a burguesia nos prometia é a velha imagem já bem nossa conhecida: a de uma classe opressora que monopoliza a riqueza e a cultura diante de uma classe oprimida, para a qual só é permitida a superstição religiosa e um saber bem dosado (PONCE, 2003, p. 172. 
Diante disso, a escola assume papel preponderante de inculcação e conformismo, silenciando através da alienação as aspirações das massas trabalhadoras oprimidas que passam a atender os interesses do mundo do trabalho e a reproduzir as ideologias dominantes. Isto ocorre, segundo Althusser (1985), devido à grande contribuição da escola enquanto um Aparelho Ideológico de Estado que determina as relações entre explorados e exploradores dentro de uma formação social capitalista.

Assim, sobre a premissa de educação universal e neutra com profissionais capazes de conduzir os alunos à liberdade, à moralidade, ao conhecimento acumulado historicamente, a escola hegemonicamente cumpre, tanto no campo instrumental quanto ideológico, a função reprodutora da relação de exploração capitalista.

Sobre isso, vale considerar que para vigorar esse plano ideológico é preciso que este se reproduza, porém esta reprodução não se resume a uma simples repetição mecanicista, visto que "a luta pela reprodução da ideologia dominante é um combate inacabado que sempre é preciso retomar e que sempre está submetido à lei da luta de classes" (ALTHUSSER, 1985, p. 111).

Nessa perspectiva, ainda que evidente e hegemônico o caráter conservador da escola no capitalismo, é necessário termos uma visão mais analítica, a partir de uma perspectiva do materialismo histórico-dialético, compreendendo as contradições presentes na função unilateral do sistema educacional.

A escola, enquanto instrumento do conformismo científicotecnológico, expressão contemporâneo da sociabilidade humana, ao mesmo tempo em que veicula ideologias reprodutoras das relações sociais dominantes, veicula também ideologias antagônicas e contraditórias... (NEVES, 2002).

Sendo assim, é preciso ressaltar que o capitalismo em sua fase monopolista exige da escola, frente ao binômio industrialismo/democracia, o nivelamento de conhecimento e a formação de técnicos e dirigentes sob controle hegemônico, como forma de garantir a racionalização do trabalho 
(NEVES, 2002). No entanto, considerando a ótica do trabalho, é na escola, mediante suas contradições, que o industrialismo e a democracia significam inserção técnica e política para compreender e transformar as relações de produção vigentes através das lutas contra a apropriação privada da riqueza e do saber (NEVES, 2002).

\section{Reestruturação produtiva: reafirmando a concepção unilateral de formação humana}

Conforme exposto, na ótica burguesa, os sistemas escolares objetivam adequar ideológica e instrumentalmente o sujeito para atender exclusivamente as exigências da produção capitalista. Desta forma, o ideal formativo escolar vincula-se às necessidades mercantis, obedecendo às determinações históricas dos modelos de produção predominante em cada fase do capitalismo. Isto é, os objetivos dos sistemas escolares, hegemonicamente, refletirão as necessidades de qualificação impostas pelo mercado de trabalho. "Neste sentido, o projeto pedagógico que ocorre no interior da fábrica articula-se com o processo educativo em geral, que se desenvolve no conjunto das relações sociais determinadas pelo capitalismo." (Kuenzer, 2002, p. 76).

A partir desta constatação, para compreender o papel da escolarização na formação humana, é necessário fazer uma análise da organização da produção, do padrão produtivo vigente em cada momento histórico. Assim, para entender a concepção sócioeducativa vivenciada atualmente, precisa-se analisar o processo de crise do padrão produtivo taylorista-fordista (evidenciado a partir de 1970) e sua substituição por uma produção flexível, cujo modelo mais bem sucedido é o toyotismo (ANTUNES, 2005).

O binômio taylorismo-fordismo caracterizou-se como um modelo produtivo de caráter rígido, cuja finalidade era controlar a intensa fragmentação das atividades produtivas. Nesse modelo (com uma produção padronizada, em série e em massa) exigia-se do trabalhador um conhecimento superficial, sem a compreensão do processo produtivo como um todo (SOUZA NETO; LIBERAL, 2004) e destacava-se uma clara segregação entre atividades intelectuais e instrumentais. Assim sendo, a 
análise de Kuenzer (2002) auxilia na compreensão deste cenário, pois quanto mais mecanizado for a produção,

mais ele se fragmenta e automatiza, menos domínio do saber sobre o trabalho total ele exige, menos energias intelectuais e criativas ele mobiliza; gerido externamente pelo capitalista, cuja eficácia repousa na divisão do trabalho, na ruptura entre decisão e ação, entre trabalho intelectual e manual, ele passa a ser desinteressante e monótono. (p. 77).

Desta forma, a especialização exacerbada para funções laborais restritas e repetitivas consubstancia-se no ideal formativo do fordismo. Logo, no cenário educacional há uma demanda em ofertar, para a classe trabalhadora, cursos técnicos de adestramento rígido, reforçando ideologicamente o tecnicismo pedagógico como responsável pelo desenvolvimento social e econômico, tanto na esfera individual quanto na coletiva.

Entretanto, com as mudanças no mundo produtivo, evidenciadas a partir de 1970 como uma contra-ofensiva do capital aos direitos sociais conquistados pelos trabalhadores após a $2^{\mathrm{a}}$ Guerra (principalmente nos países desenvolvidos), com a crescente inserção das tecnologias no modo de produção tem-se a necessidade de um novo perfil de trabalhador. Em função do fracasso da produção fordista, como conseqüência da crise estrutural do capital, intensifica-se o processo de expropriação do trabalho, seja através de sua precarização, em todas as formas, ou por meio da exigência de novos mecanismos exploradores (ANTUNES, 2005).

Neste sentido, o final do século XX será marcado pela intensificação de "uma estrutura produtiva mais flexível, recorrendo freqüentemente à desconcentração produtiva, às empresas terceirizadas etc." (ANTUNES, 2005 , p. 52). Esta reconfiguração na conjuntura produtiva, utilizando-se de novas técnicas de trabalho, exige dos trabalhadores maior envolvimento na gestão laboral a partir das "células de produção".

O ideário exposto, ressaltando a necessidade de um sujeito polivalente e preparado para trabalhar em equipe, exige maior domínio intelectual do trabalhador e, por isso, apresenta-se como constituinte de melhores 
condições laborais. Entretanto, conforme ressalta Antunes (2005), o novo modelo não propõe mudanças nas estruturas de trabalho em favor do trabalhador, mas apenas uma reorganização do processo produtivo, de modo que, o empregador se aproprie de maneira mais intensa das habilidades intelectuais até então ignoradas.

A nova fase do capital, portanto, transfere o savoir faire para o trabalho, mas o faz apropriando-se crescentemente da sua dimensão intelectual, das suas capacidades cognitivas, procurando envolver mais forte e intensamente a subjetividade operária. Mas o processo não se restringe a esta dimensão, uma vez que parte do saber intelectual é transferido para as máquinas informatizadas, que se tornam mais inteligentes, reproduzindo parte das atividades a elas transferidas pelo saber intelectual do trabalho. Como a máquina não pode suprimir o trabalho humano, ela necessita de uma maior interação entre a subjetividade que trabalha e a nova máquina inteligente. (ANTUNES, 2000, p. 42-3).

Como conseqüência desta reconfiguração produtiva impõese permanentemente aos trabalhadores a necessidade de buscarem competências profissionais flexíveis. Ao indivíduo recai a responsabilidade de manter-se o tempo todo qualificado, ou seja, empregável, caso contrário, ficará alijado da possibilidade de, pelo menos, disputar um emprego.

Os efeitos da crise do padrão produtivo fordista levaram, obviamente, a uma reconfiguração dos objetivos formativos dos sistemas de ensino - trata-se para o grande capital de estabelecer os mecanismos necessários para adequar a educação do trabalhador às exigências da "sociedade do conhecimento". Os sistemas educacionais precisam passar por um conjunto de reformas com o intuito de atender os novos padrões de formação de mão-de-obra.

Diante da nova conjuntura, enfatiza-se a chamada pedagogia das competências, promotora de habilidades intelectuais e práticas. Tratase de projetar uma formação escolar capaz de oferecer ao trabalhador "o desenvolvimento da capacidade de educar-se permanentemente e 
das habilidades de trabalhar independentemente, de criar métodos para enfrentar situações não previstas, de contribuir originalmente para resolver problemas complexos." (KUENZER, 1998, p. 73).

\section{A concepção omnilateral de formação}

A submissão da função social da escola aos desígnios do capital é evidenciada quando a preparação para o trabalho, promovida por essa instituição, representa uma dependência ao sistema produtivo (PARO, 2001). Assim, ainda que com objetivos formativos mais intelectualizados, a ênfase na valorização da pedagogia das competências significa apenas uma readequação dos propósitos educacionais às novas necessidades produtivas pós-fordistas, qual seja, formar para a empregabilidade.

Neste sentido, a formação para a empregabilidade, ao contrário do que apregoa os apologetas do capital, não significa possibilidade de realização humana, mas a exacerbação da individualidade e da competitividade. De acordo com Paro, "servir ao capital tem sido o grande erro da escola básica" (2001, p. 23) e, diante disto, cabe-nos um repensar sobre o ideal de formação que a escola deve proporcionar enquanto espaço de disseminação e construção de conhecimentos em todas as dimensões humanas.

De acordo com Libâneo (2003), a implementação da pedagogia das competências, que induz à idéia de melhoria da qualidade de ensino e qualificação profissional, não sinalizam a construção de uma educação democrática e formadora de cidadania. Ao primar pela competitividade entre os indivíduos esta pedagogia ignora a possibilidade de uma formação que atenda aos interesses humanos. Para Libâneo a educação de qualidade "é aquela mediante a qual a escola promove, para todos, o domínio dos conhecimentos e o desenvolvimento de capacidades cognitivas e afetivas indispensáveis ao atendimento de necessidades individuais e sociais" (2003, p. 118).

Esta perspectiva formativa exige uma escola unitária, a qual seja capaz de proporcionar uma qualificação humana com o "desenvolvimento de condições físicas, mentais, afetivas, estéticas e lúdicas do ser humano (condições omnilaterais) capazes de ampliar a capacidade de trabalho na produção de valores de uso em geral" (FRIGOTTO, 2003, p. 31-2). 
No plano da construção da escola unitária, omnilateral, a educação precisará partir da realidade dos sujeitos sociais e não concebê-lo na ótica individualizada. A concepção de integração entre realidade social e escola evidencia dizer que estes segmentos estão diretamente relacionados e que, portanto, o conhecimento a ser desenvolvido deve ser orgânico (FRIGOTTO, 2003).

Logo, mais do que romper com os arbitrários educacionais, os quais são responsáveis por todo o atraso da formação humana, a formação omnilateral representa uma visível exigência pela qualificação da força de trabalho, para a efetivação do processo social e educacional em todas suas dimensões. Tendo o trabalho, desalienado, como princípio educativo, a escola unitária transcende à promessa da empregabilidade e da formação flexível, almejando um sujeito conscientemente construtor de realidade social.

\section{Transitoriedade entre o real e o ideal}

Ao analisar a contribuição da escola na sociedade capitalista para a superação da opressão humana é necessário apresentar uma premissa básica: a eliminação do capital se dará de forma global, ou seja, não se podem buscar reformas pontuais e específicas deste ou daquele instrumento de legitimidade dos valores e condutas burguesas.

A partir desta constatação, Mészáros evidencia que "uma reformulação significativa da educação é inconcebível sem a correspondente transformação do quadro social no qual as práticas educacionais da sociedade devem cumprir as suas vitais e historicamente importantes funções de mudança" (2005, p. 25).

Esta premissa basilar auxilia na constituição de horizontes teóricos e práticos coerentes ao desafio e objetivo proposto: um outro modelo societário, no qual homens e mulheres sejam efetivamente livres de todas as formas de opressão. Em outras palavras, a compreensão da necessidade de superação estrutural do capital evita projeções ingênuas e descontextualizadas, as quais, ao contrário de auxiliar na sua superação, servem como legitimadoras do atual sistema sóciometabólico.

Deste modo, no campo sócioeducativo se rejeitam, como elementos sustentadores de análise, tanto os novos objetivos pedagógicos (ancorados na 
reestruturação produtiva e no pensamento neoliberal) quanto "à perspectiva do pós-modernismo centrada na diferença, alteridade, subjetividade, particularidade e localismo" (FRIGOTTO, 1995, p. 80).

Neste cenário, reafirma-se a necessidade de se ter como ancoragem teórico-metodológica, para analisar a política educacional e o papel da escolarização atual na consolidação de uma nova sociedade, o materialismo histórico, rejeitando tanto o determinismo mecanicista da economia quanto o subjetivismo hipertrofiado e autonomizado. Com isso, ressalta-se o caráter histórico constituintes das determinações e transformações sociais conforme entende Frigotto:

Trata-se da célebre tese de Marx de que "os homens fazem a história, mas não em condições escolhidas por eles". As condiçôes não escolhidas se referem a um conjunto de determinações que produziram uma determinada estrutura e superestrutura social que nos condiciona. Não se trata, porém, de uma estrutura e superestrutura produzida por uma causalidade relacionada às forças da natureza, mas de um processo teleológico tecido nas relações de força ou de poder entre os próprios seres humanos. Trata-se pois de estruturas e determinações socialmente produzidas e, portanto, socialmente passíveis de serem alteradas pela ação consciente dos sujeitos humanos (2004, p. 63).

Além destas premissas um outro elemento indispensável nesta análise é abandonar a ilusão da escola burguesa ser um instrumento de ascensão social. Tanto na formulação clássica da Teoria do Capital Humano, quanto em sua nova concepção (mais individualizada e competitiva), conforme evidencia Gentili (2004), a escola, no capital, não é capaz, pela própria lógica excludente do sistema de mercadorias, de promover a integração ou a promoção da melhoria de vida social.

Entretanto, reitera-se que ignorar a escola como instrumento de ascensão social não significa concebê-la como mecânica e exclusivamente reprodutora de mão-de-obra para a produção capitalista (ainda que hegemonicamente cumpra esta função), mas de entendê-la a partir de uma 
análise estrutural e superestrutural da sociedade, enfatizando o caráter histórico da luta de classes.

Deste modo, se por um lado é abandonada a concepção da escola como reprodutora mecânica da sociedade de classes, também é ressaltada a necessidade de ignorar as percepções salvacionistas da educação - ou seja, os discursos que postulam que a escolarização no capital é sinônima de emancipação humana. A partir desta perspectiva, é preciso combater a exacerbação do indivíduo como responsável, através de formação polivalente, por sua inclusão e sucesso no mundo do trabalho. Contrariamente ao discurso da empregabilidade, da pedagogia das competências, é preciso evidenciar empiricamente que "o indivíduo pode possuir determinadas condições de empregabilidade e nem por isso garantir sua inserção no mercado de trabalho" (GENTILI, 2004, p. 55), visto que a exclusão é um problema estrutural e não individual.

Diante destas constatações, entende-se ser essencial a apropriação das incoerências do projeto educativo em curso, para aprofundar a lógica estruturalmente contraditória do capital, evidenciando a impossibilidade de realização humana num sistema sóciometabólico excludente. Neste processo denunciador do fetichismo da pedagogia burguesa é necessário o fortalecimento dos movimentos sócioeducativos (independentes do Estado burguês) que projetam uma sociedade sem classes. Trata-se de colocar nossa atuação acadêmica e política em prol da luta contra os interesses unilaterais da sociedade e da escola capitalista.

\section{CONSIDERAÇÕES FINAIS}

$\mathrm{Na}$ sociedade capitalista a escolarização tem cumprido hegemonicamente a função unilateral de formação técnico-instrumental e comportamental do trabalhador para o mercado de trabalho. Entretanto, esta função unilateral não é claramente perceptível, pois é acompanhada de um discurso defensor da escolarização como instrumento de ascensão sócioeconômica dos sujeitos. Deste modo, estabelece-se um fetiche ideológico que mascara os verdadeiros fundamentos da função social da escola no capitalismo (GUIMARÃES, 2007). 
Atualmente, diante do processo de reestruturação produtiva, tanto a unilateralidade da escola burguesa, quanto o seu mascaramento ideológico se intensificam. Conforme exposto, as novas exigências de trabalhadores com qualificações intelectualizadas e multifuncionais (ignoradas no fordismo) redefinem os objetivos formativos da escolarização, porém, longe de significar uma formação humana em todas as suas dimensões, este processo mantém a submissão da função, instrumental e ideológica, da escola aos desígnios do capital.

Em contraposição ao papel hegemonicamente unilateral da educação escolar, elucida-se a necessidade de uma formação humana plena, ou seja, em condições omnilaterais, a qual só efetivar-se-á no socialismo. Neste sentido, reafirma-se a necessidade de superação estrutural da lógica desumana da sociedade capitalista. Esta constatação possibilita uma compreensão crítica e real sobre a função que a escola, dentro do sistema capitalista, pode exercer na consolidação da sociedade sem classes.

Em linhas gerais, no capitalismo, propósitos educativos que se almejem construir uma escola com formação humana plena devem, ancoradas no materialismo histórico, evidenciar o caráter segregatório, anti-humano (e essencialmente contraditório) da pedagogia burguesa e, ao mesmo tempo, ampliar os espaços e movimentos que na contracorrente lutam contra a opressão burguesa em todas as suas formas.

\section{REFERÊNCIAS}

ALTHUSSER, Louis. Aparelhos ideológicos de estado: notas sobre os aparelhos ideológicos do Estado. 10a edição. Rio de Janeiro: Edições Graal, 1985.

ANTUNES, Ricardo. Trabalho e superfluidade. In: LOMBARDI, José Claudinei; SAVIANI, Dermeval; SANFELICE, José Luis (org.). Capitalismo, trabalho e educação. Campinas: Autores Associados, 2000.

do trabalho. $7^{\text {a }}$ ed. São Paulo: Boitempo, 2005.

FRIGOTTO, Gaudêncio. Os delírios da razão: crise do capital e metamorfose conceitual no campo educacional. In: GENTILI, Pablo (org.). Pedagogia da 
e sco I a rizaça o burgu e s a...

Exclusão: crítica ao neoliberalismo em educação. Petrópolis: Vozes, 1995. p. 77108.

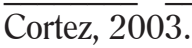

$\neg$. Estruturas e sujeitos e os fundamentos da relação trabalho e educação. In: LOMBARDI, José Claudinei; SAVIANI, Dermeval; SANFELICE, José Luís (Orgs.) Capitalismo, trabalho e educação. 2a . edição revista. Campinas: Autores Associados, 2004, p. 61-74.

GENTILI, Pablo. “Adeus à Escola pública: a desordem neoliberal, a violência do mercado e o destino da educação das maiorias". In: $\_\_\neg$. (org.). Pedagogia da Exclusão: Critica ao neoliberalismo em educação. Petrópolis: Vozes, 1995.

$\neg$. Três teses sobre a relação trabalho e educação em tempos neoliberais. In: LOMBARDI, José Claudinei; SAVIANI, Dermeval; SANFELICE, José Luís (Orgs.) Capitalismo, trabalho e educação. $2^{\mathrm{a}}$. edição revista. Campinas: Autores Associados, 2004, p. 45-59.

GUIMARÃES, André Rodrigues. Redefinição dos objetivos pedagógicos do capital: em busca de um novo consenso. Trabalho apresentado no IV Fórum Nacional de Educação e I Simpósio Internacional de Educação da ULBRA. Torres-RS, 2007.

KUENZER, Acácia Zeneida. Pedagogia da Fábrica: as relações de produção e a educação do trabalhador. 6. ed. São Paulo: Cortez, 2002.

LIBÂNEO, José Carlos. A educação escolar pública e democrática no contexto atual: um desafio atual. In: $\_\neg$ et al. Educação escolar: Políticas, estruturas e organização. São Paulo: Cortez, 2003.

NETO, João Clemente de Souza; LIBERAL, Márcia Mello Costa de. A metamorfose do trabalho na era da globalização. São Paulo: Arte Impressa, 2004.

MÉSZÁROS, István. Educação para além do capital. São Paulo: Boitempo, 2005.

NEVES, Lúcia Maria Wanderley. Educação e política no Brasil de hoje. $3^{\text {a }}$ ed. São Paulo: Cortez, 2002. 
PARO, Vitor Henrique. Parem de formar para o trabalho! Reflexões acerca dos efeitos do neoliberalismo sobre a gestão e o papel da escola básica. In:

$\neg$ _. Escritos sobre educação. - São Paulo: Xamã, 2001.

PONCE, Aníbal. Educação e luta de classes. 20a edição. São Paulo: Cortez, 2003. 